\title{
Two new species of Diaphorocellus Simon, 1893 from Madagascar (Araneae, Palpimanidae)
}

\author{
Sergei L. Zonstein', Yuri M. Marusik ${ }^{2,3}$ \\ I Steinhardt Museum of Natural History, Tel-Aviv University, 69978 Tel-Aviv, Israel 2 Institute for Biological \\ Problems of the North RAS, Portovaya Str. 18, Magadan, Russia 3 Department of Zoology \& Entomology, \\ University of the Free State, Bloemfontein 9300, South Africa
}

Corresponding author: Sergei L. Zonstein (znn@tauex.tau.ac.il)

Academic editor: B. A. Huber | Received 4 October 2019 | Accepted 17 January 2020 | Published 6 February 2020

http://zoobank.org/C1193BE3-8442-4AB6-AF7E-1683FCB609C3

Citation: Zonstein SL, Marusik YM (2020) Two new species of Diaphorocellus Simon, 1893 from Madagascar (Araneae, Palpimanidae). African Invertebrates 61(1): 1-15. https://doi.org/10.3897/AfrInvertebr.61.47048

\begin{abstract}
Two new species of the palpimanid genus Diaphorocellus Simon, 1893, D. isalo sp. nov. ( $\hat{O}$ ) ), and $D$. jocquei sp. nov. $(\hat{\partial}+)$, are described from central and eastern parts of Madagascar, respectively. Along with $D$. rufus (Tullgren, 1910), these new species can be distinguished from other congeners by possessing a finely and densely spotted colouration of the abdomen. They differ from one another, as well from $D$. rufus, by the eye group configuration and by the structure of the male and female copulatory organs. Diagnoses and illustrations presenting the diagnostic characters of $D$. isalo sp. nov. and D. jocquei sp. nov. are provided. The genus now includes six African species.
\end{abstract}

\section{Keywords}

Afrotropic realm, Chediminae, endogyne, palp-footed spiders, taxonomy 


\section{Introduction}

The spider family Palpimanidae is relatively well represented in mainland Africa, where it comprises 13 genera and 53 species vs. 18 and 150 respectively, known for the entire world (World Spider Catalog 2019). Palpimanids have also been found in several insular territories/countries located near the African continent: São Tomé and Príncipe (Simon 1907), the Seychelles (Simon 1898; Platnick 1979; Saaristo 2010) and Socotra (Pocock 1899, Zonstein et al. 2018). However, to date, no named species of the Palpimanidae have been reported from the largest of the regional islands, Madagascar, although the occurrence of Diaphorocellus spp. on this island was first noted by Wood et al. (2018).

The present study, which seeks to fill this gap, is based on the examination of palpimanid specimens deposited in the Royal Museum for Central Africa, Tervuren, Belgium (RMCA). Along with other African palpimanids kept in the RMCA spider collection, several species of Diaphorocellus Simon, 1893 were identified during the study. Two of these species, originated from Madagascar, were found to be new to science and are described below.

Currently, Diaphorocellus is a small African genus of palpimanid spiders previously known to include four species whose known distribution is restricted to Tanzania, Botswana, Namibia and South Africa (World Spider Catalog 2019). The aim of this paper is to provide a detailed description of the two new species and to update the diagnostic characters of the genus.

\section{Material and methods}

The origin of the material used in this study is noted above.

Photographs were taken using an Olympus SZX16 stereomicroscope with a Canon-7D camera and final images were compiled using Zerene Stacker 1.04 software (https://zerenesystems.com). Scanning electron micrographs were made using a JEOL JSM-5200 scanning microscope at the Zoological Museum, University of Turku, Finland. Illustrations of scuta and endogynes were made after maceration in a $20 \%$ potassium hydroxide aqueous solution and exposure for a few minutes in an alcohol solution of Chlorazol Black. Endogynes were photographed on slides with either an Olympus SZX16 or an Olympus BH-2. Background maps were taken from https:// www.simplemappr.net (Shorthouse 2010).

Measurements were made to an accuracy of $0.01 \mathrm{~mm}$. Lengths of leg and palp segments were measured on the dorsal side, from the midpoint of the anterior margin to the midpoint of the posterior margin. All measurements are given in millimetres. Terminology partially follows Zonstein et al. (2016).

The following abbreviations (except those encoded in the captions) are used in the article: ALE - anterior lateral eye(s), AME - anterior median eye(s), $\mathbf{C H}$ - carapace height, $\mathbf{C L}$ - carapace length, $\mathbf{C W}$ - carapace width, $\mathbf{C y L}$ - clypeus length, $\mathbf{L} / \mathbf{W}$ ratio length/width, PLE - posterior lateral eye(s), PME - posterior median eye(s), TL - total length of body in dorsal view. 


\section{Taxonomy}

Family Palpimanidae Thorell, 1870
Subfamily Chediminae Simon, 1893

\section{Genus Diaphorocellus Simon, 1893}

Diaphorocellus Simon, 1893: 314; Platnick 1975: 5; Zonstein et al. 2016: 96.

Type species. Diaphorocellus biplagiatus Simon, 1893, by monotypy.

Notes. Diaphorocellus appears to be an exclusively Afrotropical chedimine genus that comprises six species: D. albooculatus Lawrence, 1927 (Namibia), D. biplagiatus Simon, 1893 (South Africa), D. helveolus (Simon, 1910) (Botswana), D. isalo sp. nov. (Madagascar), D. jocquei sp. nov. (Madagascar) and D. rufus (Tullgren, 1910) (Tanzania). Within the genus, the first three species have a bicoloured dorsal abdominal pattern (presenting a broad longitudinal pale stripe against a dark background, the pale stripe is usually separated into two by a wide dark bridge). These congeners differ from the remaining three species, which have a uniformly and finely spotted abdominal colouration. To date, only the type species, $D$. biplagiatus, has been redescribed in detail (Zonstein et al. 2016).

\section{Diaphorocellus isalo sp. nov.}

http:/zoobank.org/6B99BCC0-B4BC-4865-8E19-7AF5E7591989

Figs $1 \mathrm{~A}-\mathrm{D}, 2 \mathrm{~A}-\mathrm{B}, 3 \mathrm{~A}-\mathrm{B}, 4 \mathrm{~A}-\mathrm{C}, 5 \mathrm{~A}-\mathrm{B}, 6 \mathrm{~A}, 7 \mathrm{~A}-\mathrm{D}, 8 \mathrm{~A}, 9$

Etymology. The specific name is a toponym referring to the type locality, Isalo.

Types. Holotype ${ }^{\lambda}$, and paratype +9 from Madagascar, Fianarantsoa Province,

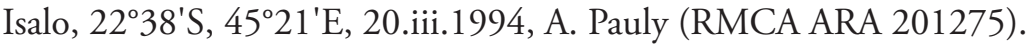

Diagnosis. The holotype male of $D$. isalo sp. nov. can be distinguished from the males of $D$. jocquei sp. n. by its larger size (CL 2.25 vs. 2.0), by presence of the cymbial spines vs. absence, and by the tapering prolateral arm of the tegular apophysis vs. widened arm. Females of these two species clearly differ in the shape of the membranous sacs of the endogyne: small globular in $D$. isalo sp. nov. vs. large subconical in $D$. jocquei sp. nov. In $D$. isalo sp. nov. the PME almost touch each other, while in $D$. isalo sp. nov. these eyes are slightly distant from each other (Figs $2 \mathrm{~A}-\mathrm{B}$ cf. Figs $2 \mathrm{C}-\mathrm{D}$ ). Additionally, $D$. isalo sp. nov. differs from $D$. biplagiatus by possessing a finely spotted dorsal abdominal pattern, as well as by lacking very long retrolateral setae of the male palp, by having a short palpal femur (length/width ratio 2.3 vs. 3.2) and by presence of the membranous sacs in the endogyne (vs. absent). Other diagnostic characters of $D$. isalo sp. nov. are noted in the Discussion.

Description. Male. RMCA ARA 201275 (holotype).

Habitus: as in Figs 1A-B. Colour in alcohol: carapace, chelicerae and dorsal abdominal scutum dark carmine brown; legs I intense reddish orange; palps and legs II-IV 

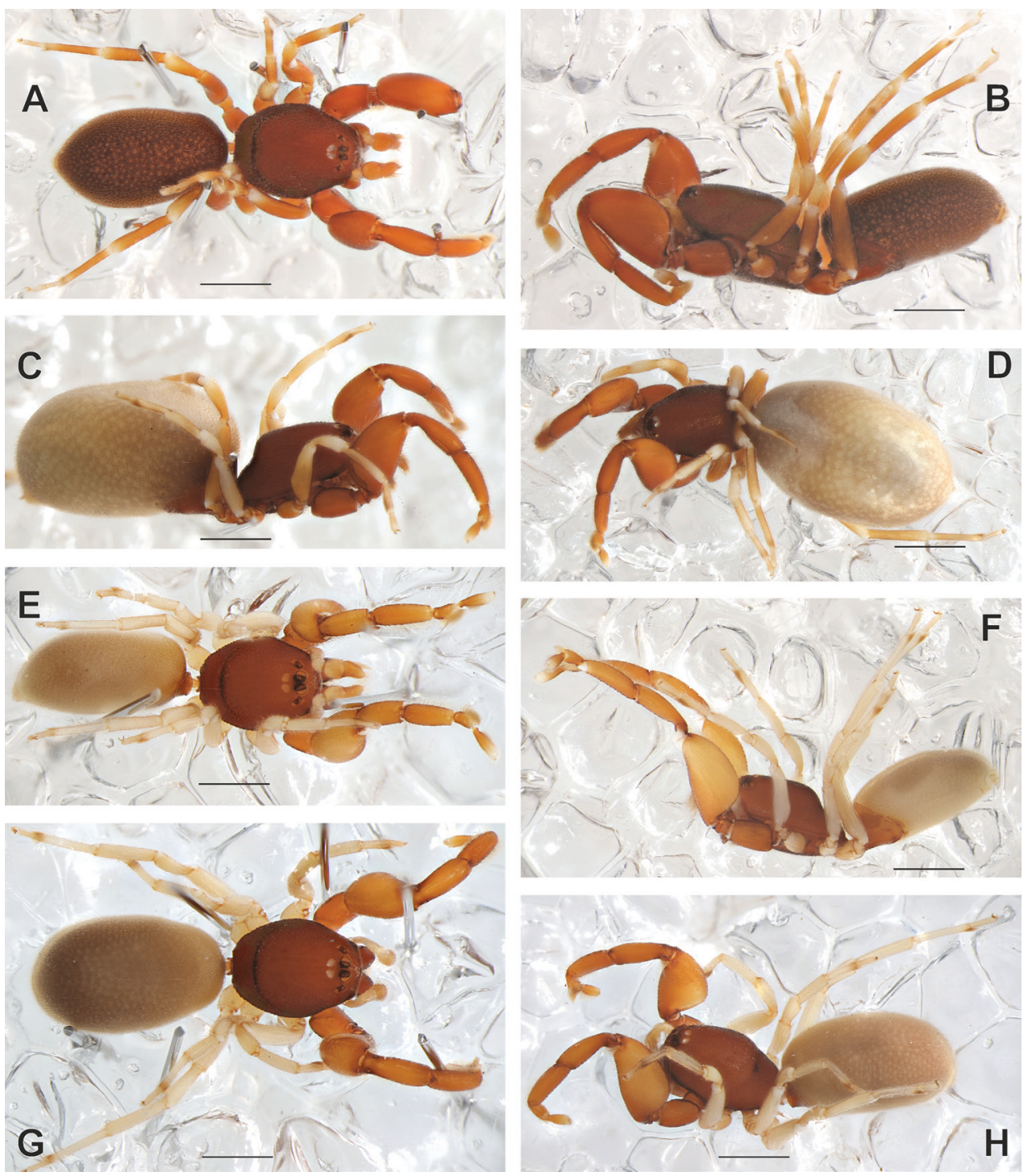

Figure I. Habitus of Diaphorocellus isalo sp. n (A-D) and D. jocquei sp. n. (E-H). A, E male, dorsal B, F male, lateral $\mathbf{C}, \mathbf{H}$ female, lateral $\mathbf{D}, \mathbf{G}$ female, dorsal. Scale bar: $1.0 \mathrm{~mm}$.

light to medium yellowish orange; sternum, labium, maxillae and ventral abdominal scutum reddish brown; abdomen dorsally dark brown with numerous light yellowish brown spots, ventrally uniformly medium yellowish brown. Measurements: TL 4.50, CL 2.10, CW 1.45, CH 0.95, CyL 0.29, Femur I L/W 1.88 (1.50/0.80). Carapace: with rather coarse granulations (Fig. 2A). Eyes: AME 0.14, ALE 0.09, PME 0.13, PLE 0.07, AME-AME 0.04, AME-ALE 0.07, PLE-PME 0.14, PME-PME 0.01.

Copulatory organs. Palp as shown in Figs 4A-C, 5A-B, 6A. Femur 2.6 times longer than wide, 1.2 times longer than cymbium; patella globular, thinner than femur; tibia swollen, as long as wide, 1.4 times wider than femur. Cymbium antero-retrolaterally 
with tight bunch of strong spines, retrolaterally with dense brush of thick setae. Bulb globular, partly embedded into tibia, with two long (longer than tegulum) extensions: tegular apophysis and embolus. Tegular apophysis with two arms, pro- and retrolateral; prolateral arm with kind of comb on inner side; both arms bent on tip. Embolus located prolaterally, flat and long, almost as long as tegular apophysis.

Leg measurements: male RMCA ARA 201275 (female RMCA ARA 201275 in brackets):

\begin{tabular}{ccccccc}
\hline & Femur & Patella & Tibia & Metatarsus & Tarsus & Total \\
\hline Palp & $0.53(0.63)$ & $0.16(0.27)$ & $0.34(0.35)$ & - & $0.44(0.42)$ & $1.47(1.67)$ \\
I & $1.50(1.63)$ & $1.05(1.25)$ & $0.93(1.05)$ & $0.33(0.40)$ & $0.43(0.45)$ & $4.24(4.78)$ \\
II & $1.05(1.25)$ & $0.63(0.63)$ & $0.70(0.88)$ & $0.50(0.58)$ & $0.38(0.40)$ & $3.26(3.74)$ \\
III & $0.90(1.00)$ & $0.50(0.58)$ & $0.65(0.70)$ & $0.55(0.63)$ & $0.38(0.35)$ & $2.98(3.26)$ \\
IV & $1.25(1.50)$ & $0.70(0.88)$ & $1.00(1.25)$ & $0.88(1.05)$ & $0.45(0.43)$ & $4.28(5.11)$ \\
\hline
\end{tabular}

Female. RMCA ARA 201275 (paratype).

Habitus: as in Figs 1C-D. Colour in alcohol: as in male, but legs II-IV and abdomen paler. Measurements: TL 6.50, CL 2.25, CW 1.55, CH 0.85, CyL 0.31, Femur I L/W 1.85 (1.63/0.88). Carapace: longer, with less coarse granulations than in male (Fig. 2B). Eyes: AME 0.12, ALE 0.07, PLE 0.07, PME 0.13, AME-AME 0.04, AMEALE 0.07, PME-PLE 0.14, PME-PME 0.01. Epigastral scutum entire (fused dorsally), with a pair of round plaque-like structures dorsally, book lung operculum large, extends above petiolar orifice.

Copulatory organs: as in Figs 3B, 7A-D, 8A. Epigastral plate in intact specimen accompanied by 2 pairs of sclerites lying on postgastrum (posterior from epigastral furrow): two small dot-like median sclerites and pair of longitudinal sclerites. Endogyne formed by pair of complex receptacles. Receptacle $(R e)$ consists of complex sclerotised base and transparent, membranous cylindric sac (Figs 7A-D). Each receptacle accompanied by brushes of fine threads and 3 grape-shaped glands attached to receptacles by long thread-like stems.

Note. Following maceration of the epigastral scutum, two additional pairs of dotlike sclerites were revealed (Fig. 7C).

Habitat. According to the collecting data, the specimens were found near a natural pool in a rocky massif.

Distribution. Known only from the type locality (Fig. 9).

\section{Diaphorocellus jocquei sp. nov.}

http:/zoobank.org/EED2889D-011A-4F9F-9D7F-5C1D9A364734

Figs $1 \mathrm{E}-\mathrm{H}, 2 \mathrm{C}-\mathrm{D}, 3 \mathrm{C}-\mathrm{D}, 4 \mathrm{D}-\mathrm{F}, 5 \mathrm{C}-\mathrm{D}, 6 \mathrm{~B}-\mathrm{C}, 7 \mathrm{E}-\mathrm{F}, 8 \mathrm{~B}, 9$

Etymology. The specific name is a patronym in honour of the prominent Belgian arachnologist, Dr Rudy Jocqué, for his highly significant contribution to the study of African spiders. 

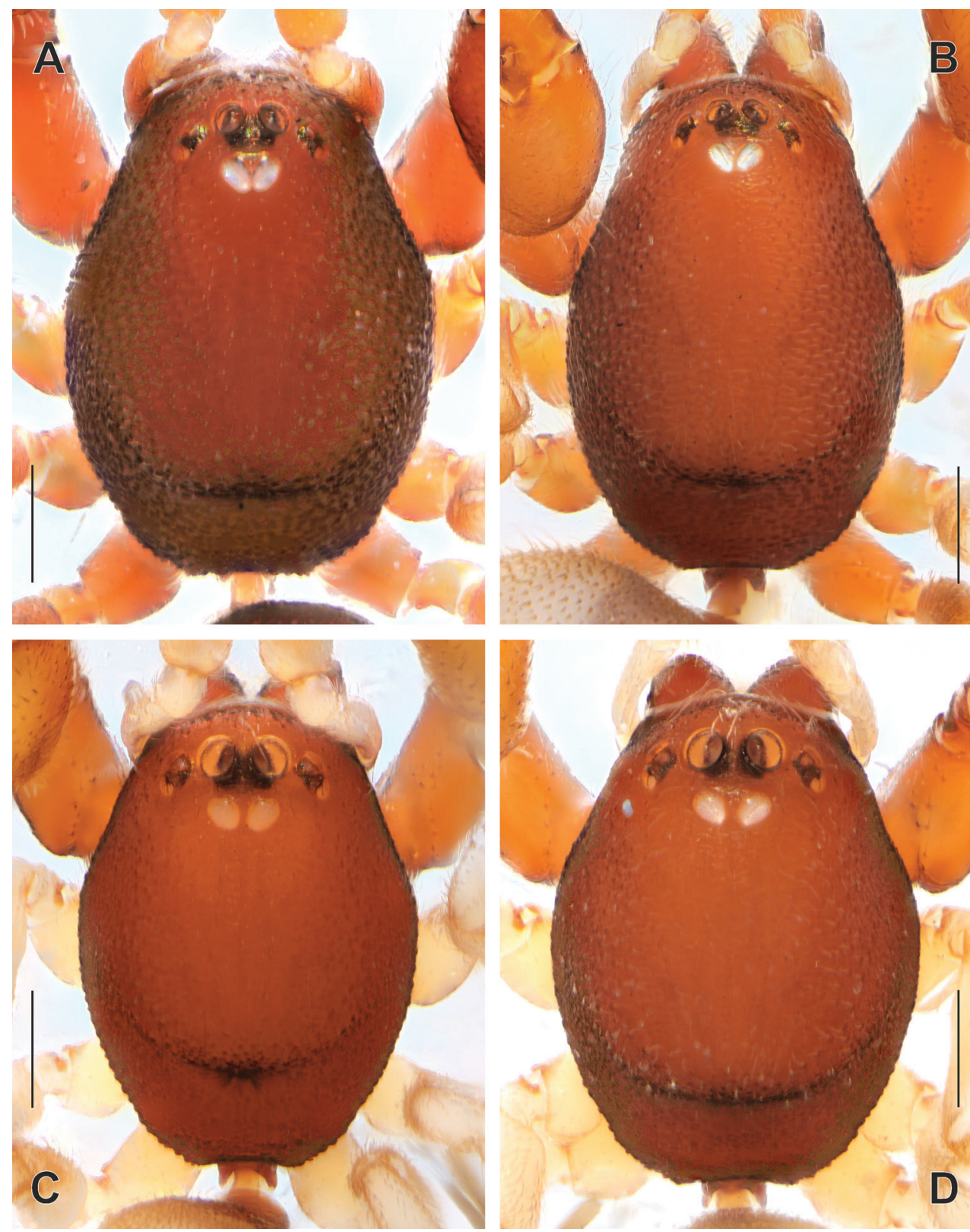

Figure 2. Prosoma, dorsal of Diaphorocellus isalo sp. nov. (A-B) and D. jocquei sp. nov. (C-D). A, C male B, D female. Scale bar: $0.5 \mathrm{~mm}$.

Types. Holotype ${ }^{\lambda}$, Madagascar, Tamatave Province, Mahavelona ("Foulpointe", as labelled), $17^{\circ} 40^{\prime}$ S, 49³1'E, 25.xi.1993, A. Pauly (RMCA ARA 200305). Paratypes: 1 , , collected together with the holotype (both deposited in the same vial); $1 \hat{O}$, 

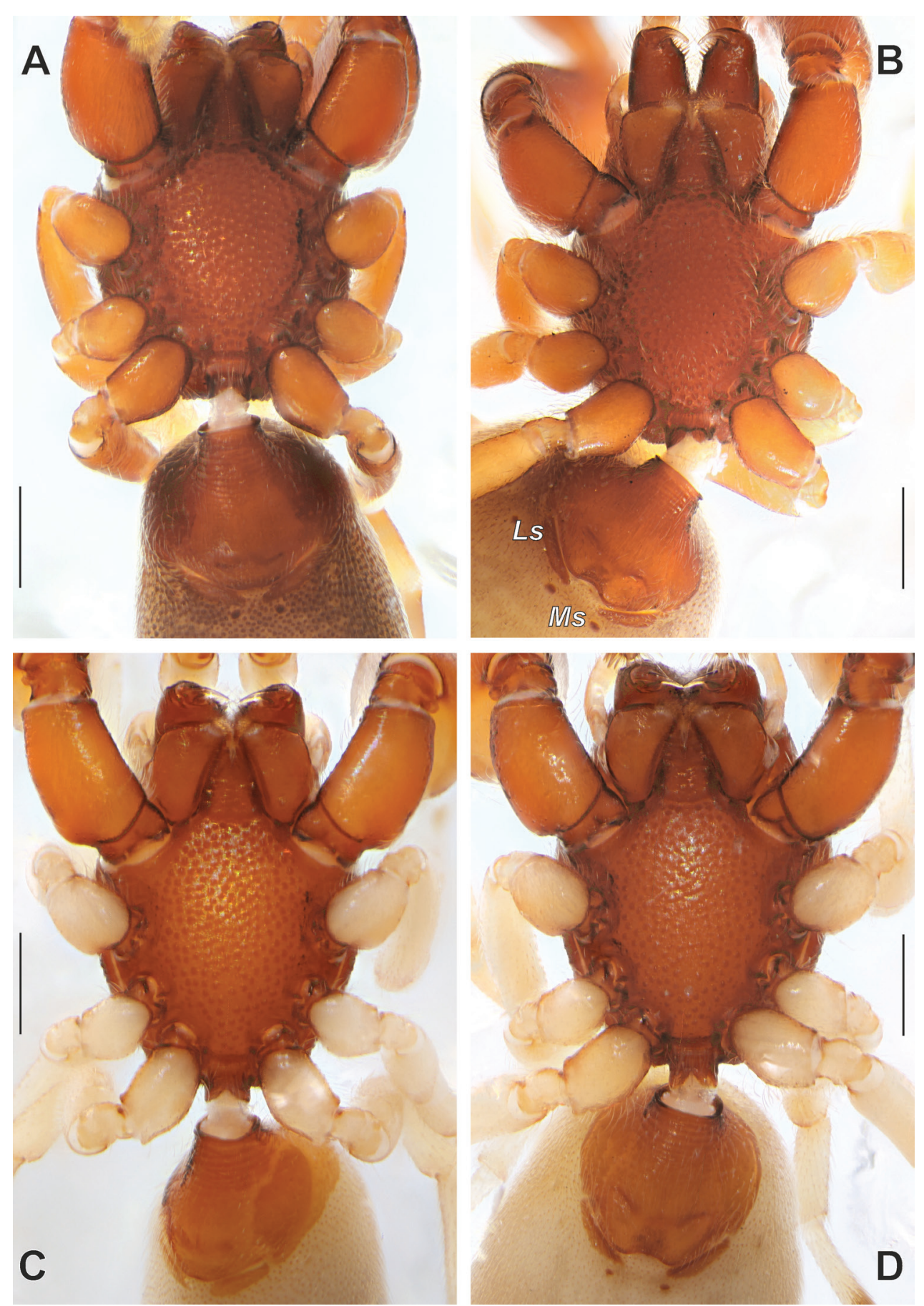

Figure 3. Prosoma, ventral of Diaphorocellus isalo sp. nov. (A-B) and D. jocquei sp. nov. (C-D). A, C male B, $\mathbf{D}$ female. Scale bar: $0.5 \mathrm{~mm}$. 

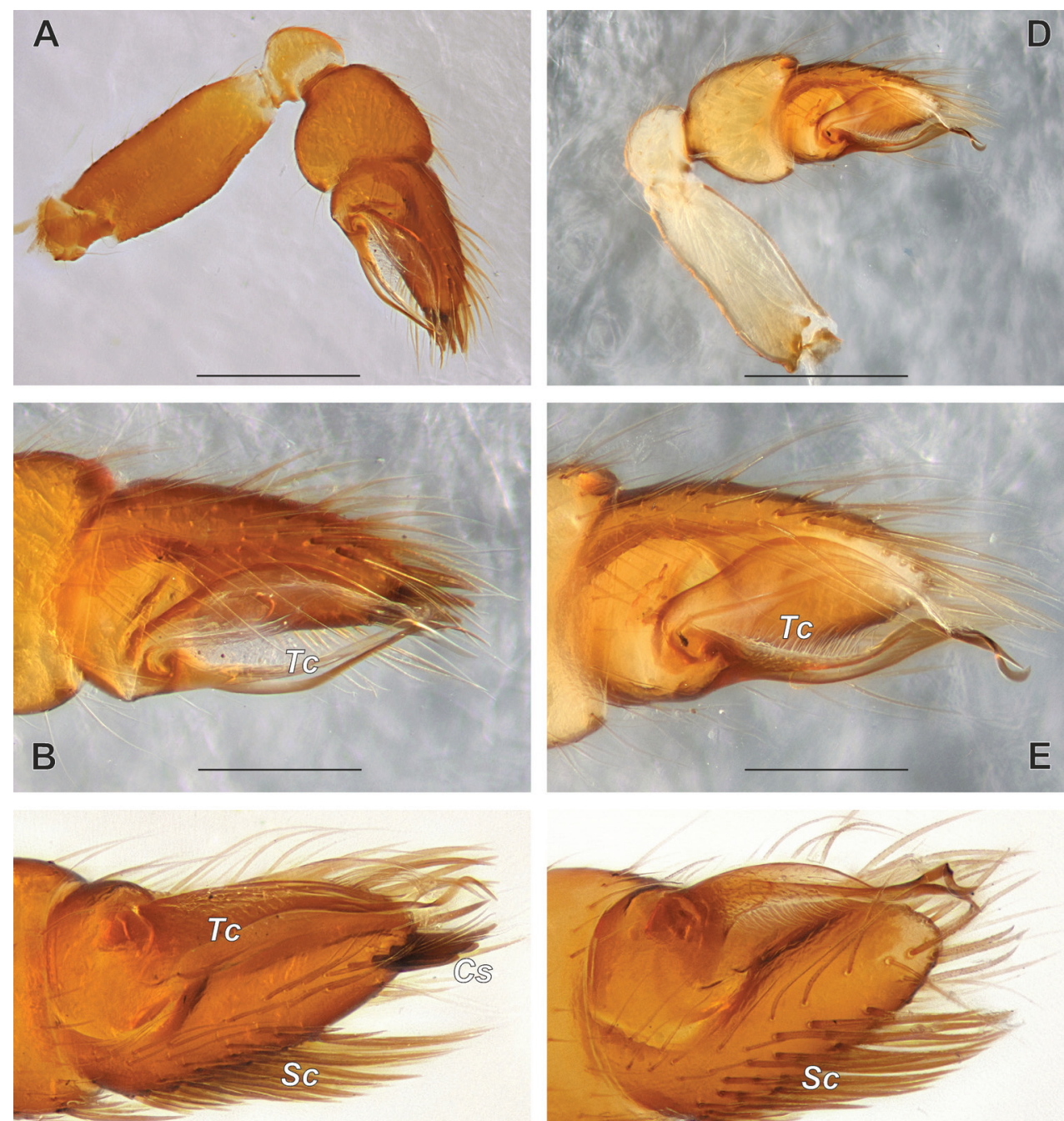

C

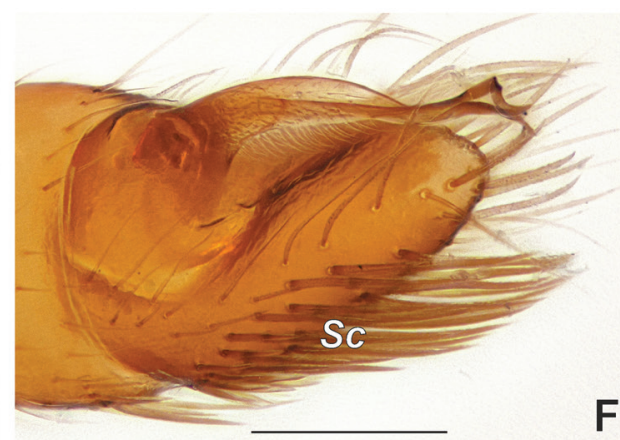

Figure 4. Male palp of Diaphorocellus isalo sp. nov. (A-C) and D. jocquei sp. nov. (D-F). A, D entire palp, prolateral $\mathbf{B}, \mathbf{E}$ terminal part, prolateral $\mathbf{C}, \mathbf{F}$ terminal part, ventro-retrolateral. Abbreviations: $C s$ cymbial spines; $S c$ brush of thick setae on cymbium; $T c$ comb of prolateral arm of tegular apophysis. Scale bar: $0.2 \mathrm{~mm}$.

1ㅇ, same collecting data but xii.1993 (RMCA ARA 177889); 1옹 same collecting data but xi.1994 (RMCA ARA 206925).

Diagnosis. The new species can be distinguished from $D$. isalo sp. nov. by its smaller size and by the shape of the copulatory organs (the latter also distinguishes this new species from non-Malagasy congeners). Males of $D$. jocquei sp. nov. are characterised by the absence of cymbial spines (vs. present), and by a less dense cymbial brush composed of stronger setae (Figs 4F cf. Fig. 4C). Females of these two species clearly differ in the shape of the membranous sacs: large subconical sacs in D. jocquei sp. nov. 

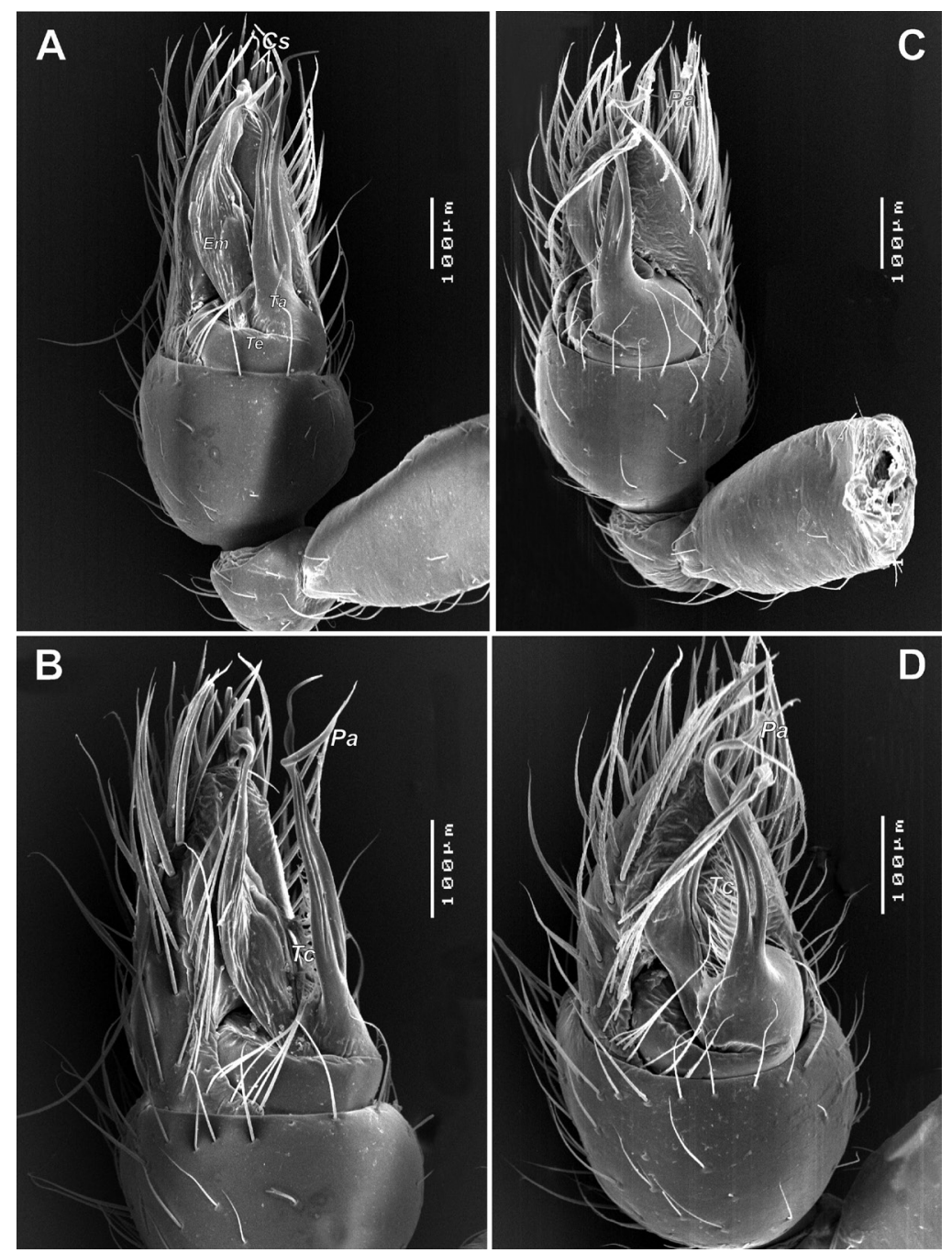

Figure 5. SEM micrograph of the male palp of Diaphorocellus isalo sp. nov. (A-B) and D. jocquei sp. nov. (C-D). A, $\mathbf{C}$ entire palp, ventral $\mathbf{B}, \mathbf{C}$ terminal part, prolateral. Abbreviations: $C s$ cymbial spines; Em embolus; Pa prolateral arm of tegular apophysis; Ta tegular apophysis; $T c$ comb of prolateral arm of tegular apophysis; Te tegulum.

vs. globular ones in $D$. isalo sp. nov. In $D$. jocquei sp. nov. the PME are slightly distant from each other, while in $D$. isalo sp. nov. these eyes almost touch each other (Figs 2C-D cf. Figs 2A-B). Additionally, D. jocquei sp. nov. differs from $D$. biplagiatus by possessing a finely spotted dorsal abdominal pattern, as well as by lacking very long retrolateral setae of the male palp, by having a shorter palpal femur (length/width ratio 2.8 vs. 3.2) and by presence of the membranous sacs in the endogyne (vs. absent). Other diagnostic characters of $D$. jocquei sp. nov. are noted in the Discussion.

Description. Male. RMCA ARA 200305 (holotype). 


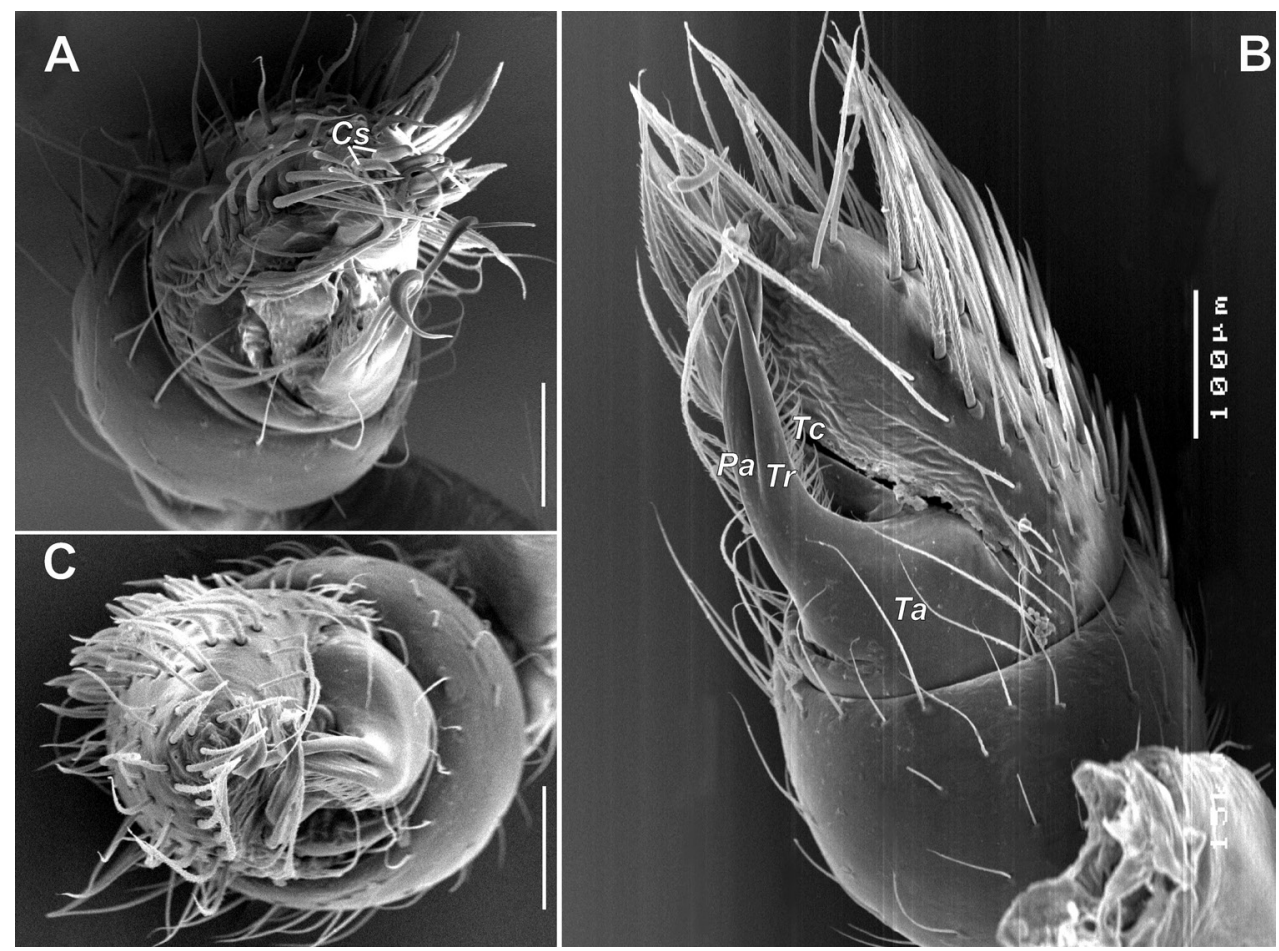

Figure 6. SEM micrograph of the male palp of Diaphorocellus isalo sp. nov. (A) and D. jocquei sp. nov. (B-C). A, $\mathbf{C}$ anterior $\mathbf{B}$ ventro-retrolateral. Abbreviations: Cs cymbial spines; Pa prolateral arm of tegular apophysis; $T c$ comb of prolateral arm of tegular apophysis; $T r$ retrolateral arm of tegular apophysis. Scale bar: $0.1 \mathrm{~mm}$.

Habitus: as in Figs 1E-F. Colour in alcohol: carapace and chelicerae deep scarlet red; legs I and abdominal scuta intense reddish orange; palps and legs II-IV pale milky orange; sternum, labium, maxillae and pedicel tube medium scarlet red; abdomen dorsally very pale brown with small and dense even paler whitish spots, ventrally uniformly pale milky orange, entirely covered with short and relatively dense brownish setae. Measurements: TL 4.35. CL 2.0, CW 1.85, CH 0.38, CyL 0.32, Femur I L/W 2.09 (1.63/0.78). Carapace: with moderately coarse granulations (Fig. 3C). Eyes: AME 0.18, ALE 0.13, PME 0.09, PLE 0.07; AME-AME 0.09, AME-ALE 0.09, AMEPME 0.07, PLE-PME 0.09, PME-PME 0.02.

Copulatory organs: Palp as shown in Figs 4D-F, 5C-D, 6B-C. Femur 2.7 times longer than wide and 1.34 times longer than cymbium; patella globular, thinner than femur; tibia swollen, as long as wide, 1.55 times wider than femur. Cymbium retrolaterally with relatively sparse brush of strong setae. Bulb globular, partly embedded into the tibia; with 2 long (longer than tegulum) outgrowths: tegular apophysis and embolus. Tegular apophysis with 2 arms, pro- and retrolateral: prolateral arm with kind of comb on inner side; both arms bent on tip. Embolus located prolaterally, flat and long, almost as long as tegular apophysis.

Leg measurements: male RMCA ARA 200305 (female RMCA ARA 200305 in brackets): 


\begin{tabular}{ccccccc}
\hline & Femur & Patella & Tibia & Metatarsus & Tarsus & Total \\
\hline Palp & $0.58(0.63)$ & $0.19(0.16)$ & $0.30(0.38)$ & - & $0.43(0.40)$ & $1.50(1.57)$ \\
I & $1.63(1.43)$ & $1.40(1.05)$ & $0.93(0.83)$ & $0.40(0.38)$ & $0.50(0.40)$ & $4.86(4.09)$ \\
II & $1.08(1.00)$ & $0.60(0.63)$ & $0.75(0.68)$ & $0.60(0.50)$ & $0.38(0.38)$ & $3.41(3.19)$ \\
III & $0.88(0.93)$ & $0.55(0.53)$ & $0.63(0.60)$ & $0.63(0.60)$ & $0.35(0.35)$ & $3.04(3.01)$ \\
IV & $1.40(1.25)$ & $0.78(0.65)$ & $1.03(1.08)$ & $0.95(0.95)$ & $0.43(0.45)$ & $4.59(4.38)$ \\
\hline
\end{tabular}
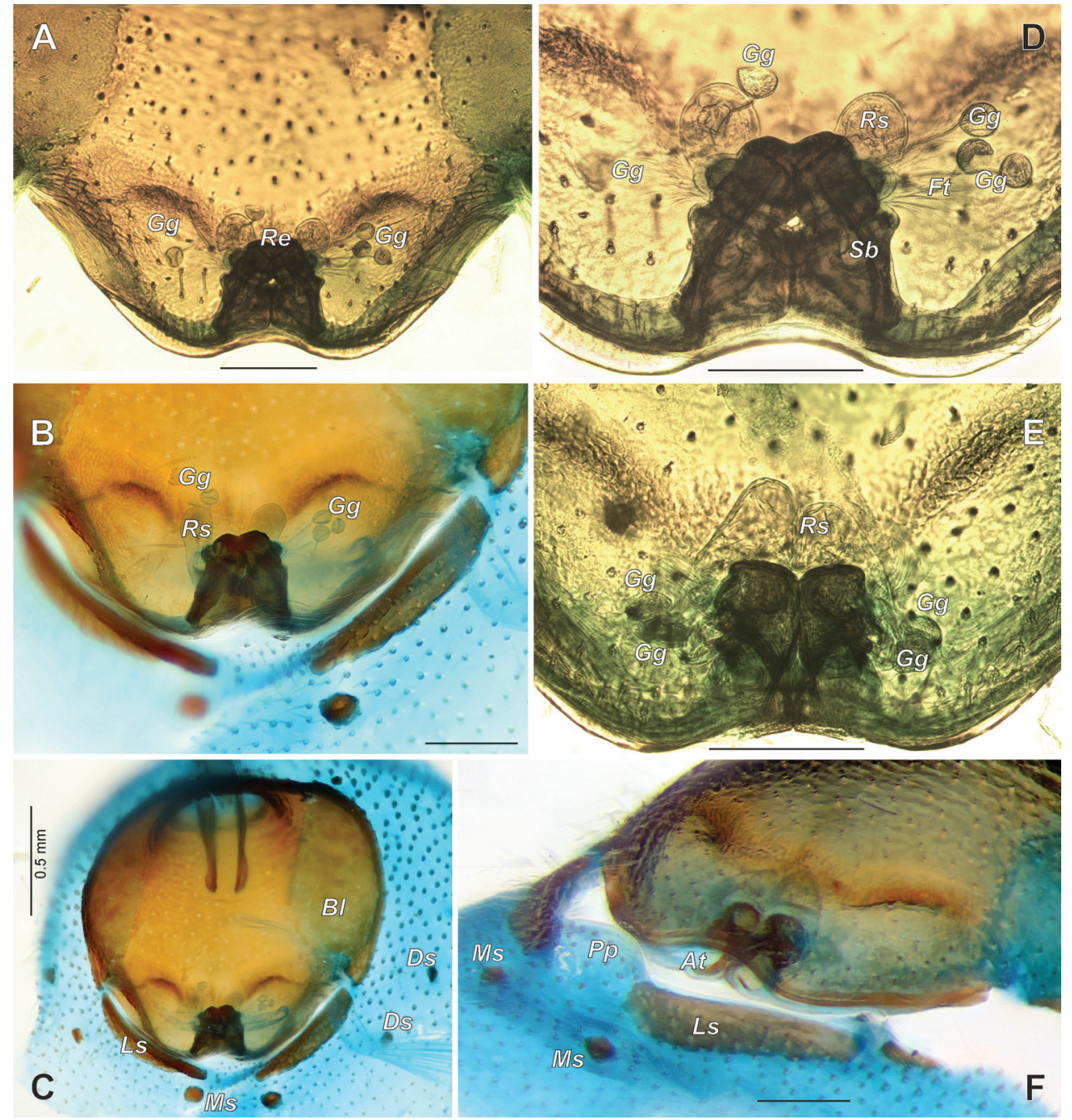

Figure 7. Female copulatory organs of Diaphorocellus isalo sp. nov. (A-D) and D. jocquei sp. nov. (E-F). A, D, E endogyne, ventral B-C epigastral scutum and anterior part of postgaster, ventral $\mathbf{E}$ - entire epigastral scutum and terminal part of postgaster showing 4 pairs of postgastral sclerites $\mathbf{F}$ epigastral sclerite and part of postgaster, postero-lateral, showing atrium and corresponding postgastral stopper. Abbreviations: At atrium; $B l$ book lung operculum; $F t$ fine threads; $G g$ grape-shaped glands; Ls longitudinal sclerites; $M s$ median sclerites; $P p$ postgastral plug; Re receptacle; $R s$ membranous cylindrical sac of receptacle; $S b$ sclerotised base. Scale bars: $0.5 \mathrm{~mm}$. 

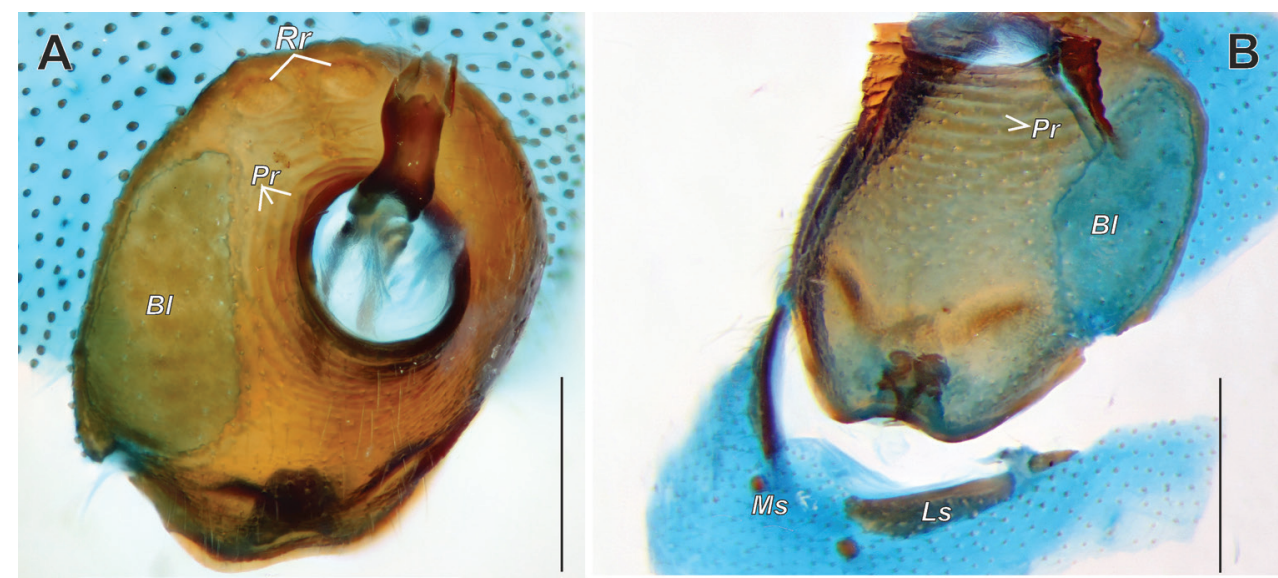

Figure 8. Anterior part of abdomen of Diaphorocellus isalo sp. nov. (A) and D. jocquei sp. nov. (B). A entire scutum, antero-lateral, showing large book-lungs $(B l)$ and round structures $(R s) \mathbf{B}$ epigastral scutum and part of postgaster, postero-ventral. Abbreviations: At atrium; $B l$ book lung operculum; $L s$ longitudinal sclerite; $M s$ median sclerite; $\operatorname{Pr}$ ridges on the petiolar tube; $R r$ round rear structure. Scale bars: $1.0 \mathrm{~mm}$.

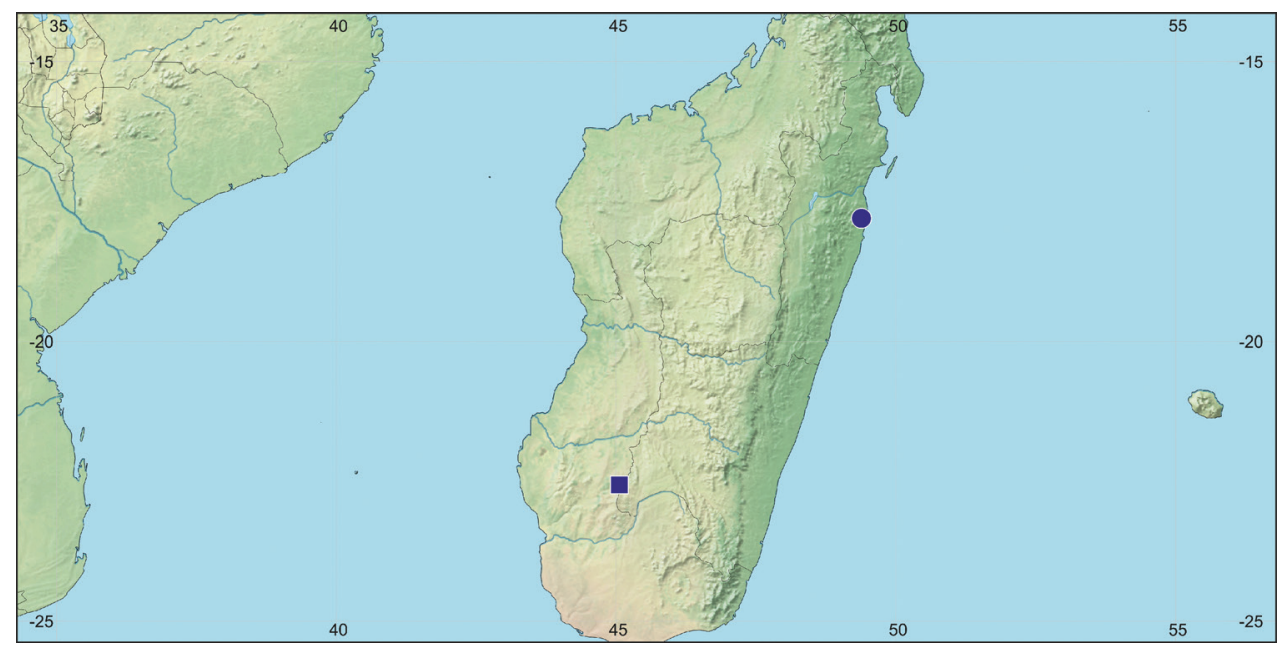

Figure 9. Records of Diaphorocellus isalo sp. nov. (square) and D. jocquei sp. nov. (circle).

Female. RMCA ARA 200305 (paratype).

Habitus: as in Figs 1G-H. Colour in alcohol: as in male, but entire body and legs I coloured slightly darker. Measurements: TL 4.75. CL 2.00, CW 1.40, CH 0.80, CyL 0.29, Femur I L/W $1.79(1.43 / 0.80)$. Carapace: longer, with less coarse granulations than in male (Fig. 2D). Eyes: AME 0.16, ALE 0.09, PME 0.09, PLE 0.14; AME-AME 0.09, AME-ALE 0.07, AME-PME 0.09, PME-PLE 0.17, PME-PME 0.02.

Copulatory organs: as in Figs 3D, 7E-F, 8B. Epigastral plate in intact specimen (before dissection) accompanied by 2 pairs of sclerites lying on postgaster (posterior to epigastral furrow): two small dot-like median sclerites and pair of longitudinal scle- 
rites. Atrium broad, postgastral plug weakly sclerotised. Endogyne formed by pair of complex receptacles. Receptacle consists of complex sclerotised base and transparent, membranous subconical sac (Fig. 7G). Each receptacle accompanied by brushes of fine threads and 3 grape-shaped glands attached to receptacles by short thread-like stems.

Habitat. According to the collecting data, the specimens were found in the litter and mosses on a forest floor, and in a fern thicket dominated by Asplenium sp.

Distribution. Known only from the type locality (Fig. 9).

\section{Discussion}

The Malagasy palpimanid species here described were assigned to Diaphorocellus because they possess similarly large PMEs (nearly equal in size to AMEs), which almost touch each other. All other eight-eyed chedimine palpimanids have PMEs that are more distant from each other and appear considerably smaller than the AMEs (Jézéquel 1964, fig. 5a-c; Benoit 1974, figs 6, 10; Deeleman-Reinhold 2001, fig. 76; Zonstein and Marusik 2013, figs. 3-6, 10, 12; 2017b, fig. 2A,C; Murphy and Roberts 2015, pl. 238; Marusik and Zonstein 2018, figs 1-3, 6); Zonstein et al. 2018, figs 4, 5).

Additionally, the structure of the male copulatory organs in $D$. isalo sp. nov. and $D$. jocquei sp. nov. appears to be much closer to that known for D. biplagiatus (Figs 4-6 cf. Zonstein et al. 2016, figs 11-15, 17, 18), than to the corresponding palpal structures in other chedimine genera. Within the Chediminae, only members of Diaphorocellus are known to possess such long and thin accessory structures, which distinguish this group from other chedimine palpimanids (cf. Jézéquel 1964, figs 2, 4, 7, 9, 11; Benoit 1974, figs 8, 9, 12, 13; Deeleman-Reinhold 2001, fig. 77; Zonstein and Marusik 2013, figs. 38-48; 2017a, figs 32-35, 49-54, 58-66; 2017b, fig. 2A,C; Marusik and Zonstein 2018, figs 8, 10, 11, 14-18; Zonstein et al. 2018, figs 8-11).

The same is true regarding the similar structure of the vulva (with the receptacles closely adjoining one another) in Diaphorocellus isalo sp. nov., D. jocquei sp. nov. and D. biplagiatus (Fig. 7A-F cf. Zonstein et al. 2016, figs 20, 23-26). It should be noted that not all the figures provided by Zonstein et al. (2016) are correct. When describing the female copulatory organs of $D$. biplagiatus, we also erroneously included two figures (Op. cit., figs 21,22) of Palpimanus sp. (from Israel) labelled as belonging to D. biplagiatus.

Both the new species from Madagascar certainly differ from D. biplagiatus in lacking a contrasting abdominal pattern, in possessing untouching posterior median eyes, shorter male palpal tibia (femur 1.2 longer than cymbium vs. 1.7), lack of long retrolateral tibial setae of the male palpal tibia, and the tegulum strongly embedded in the cymbium. The two new species feature an epigastral scutum with an extended petiolar tube; this tube and part of the scutum are provided with about 9-10 circular or subcircular ridges (Fig. 8). They differ from the similarly coloured D. rufus in eye sizes and arrangement. In both $D$. isalo sp. nov. and D. jocquei sp. nov. the distance PLE-PME only slightly exceeds the diameter of PLE, while in D. rufus, according to Tullgren (1910), the corresponding distance is 1.5 times as long as the diameter of PLE. 


\section{Acknowledgements}

We thank Arnaud Henrard and Rudy Jocqué (RMCA) for loaning us the material used for this study. Special thanks go to Ilari Sääksjärvi and Seppo Koponen (Zoological Museum, University of Turku) for providing us with museum facilities. The final draft was edited by Naomi Paz (Tel-Aviv University). We thank Arnaud Henrard, Martin J. Ramírez and an anonymous reviewer for their constructive comments. This study was supported in part by the Ministry of Absorption, Israel.

\section{References}

Benoit PLG (1974) Notules arachnologiques africaines. III. Revue Zoologique Africaine 88: 427-436.

Deeleman-Reinhold CL (2001) Forest spiders of South East Asia: with a revision of the sac and ground spiders (Araneae: Clubionidae, Corinnidae, Liocranidae, Gnaphosidae, Prodidomidae and Trochanterriidae [sic]). Brill, Leiden, 591 pp.

Jézéquel JF (1964) Araignées de la savane de Singrobo (Côte d'Ivoire). II. Palpimanidae et Zodariidae. Bulletin du Muséum National d'Histoire Naturelle 36: 326-338.

Marusik YM, Zonstein SL (2018) Notes on the spider genus Steriphopus (Araneae: Palpimanidae), with redescription of the type species. Arachnology 17(9): 491-496. https://doi. org/10.13156/arac.2018.17.9.491

Murphy JA, Roberts MJ (2015) Spider families of the world and their spinnerets. British Arachnological Society, York, 2: 191-353.

Platnick NI (1979) Contributions à l'étude de la faune terrestre des îles granitiques de l'archipel des Séchelles (Mission P.L.G. Benoit - J.J. Van Mol 1972). Araneae: Palpimanidae. Revue Zoologique Africaine 93: 461-466.

Pocock RI (1899) Descriptions of one new genus and four new species of spiders, collected in the island of Abd-el-Kuri and Sokotra. Bulletin of the Liverpool Museum 2: 7-9, 40-42.

Saaristo MI (2010) Araneae. In: Gerlach J, Marusik YM (Eds) Arachnida and Myriapoda of the Seychelles islands. Siri Scientific Press, Manchester, 8-306.

Shorthouse DP (2010) SimpleMappr, an online tool to produce publication-quality point maps. https://www.simplemappr.net. [September 02, 2019].

Simon E (1898) Etudes arachnologiques. 29e Mémoire. XLVI. Arachnides recueillis en 1895 par M. le Dr A. Brauer (de l'Université de Marburg) aux îles Séchelles. Annales de la Société Entomologique de France 66: 370-388.

Simon E (1907) Arachnides recueillis par L. Fea sur la côte occidentale d'Afrique. 1re partie. Annali del Museo Civico di Storia Naturale di Genova 3(3): 218-323.

Tullgren A (1910) Araneae. In: Sjöstedt Y (Ed.) Wissenschaftliche Ergebnisse der Schwedischen Zoologischen Expedition nach dem Kilimandjaro, dem Meru und dem Umbegenden Massaisteppen Deutsch-Ostafrikas 1905-1906 unter Leitung von Prof. Dr Yngve Sjöstedt. Stockholm 20(6): 85-172. 
Wood HM, González VL, Lloyd M, Coddington J, Scharff N (2018) Next-generation museum genomics: Phylogenetic relationships among palpimanoid spiders using sequence capture techniques (Araneae: Palpimanoidea). Molecular Phylogenetics and Evolution 127: 907918. https://doi.org/10.1016/j.ympev.2018.06.038

World Spider Catalog (2019) World Spider Catalog. Natural History Museum Bern. http:// wsc.nmbe.ch [version 20.5, accessed on 20.viii.2019]

Zonstein S, Marusik YM (2013) On Levymanus, a remarkable new spider genus from Israel, with notes on the Chediminae (Araneae, Palpimanidae). ZooKeys 326: 27-45. https://doi. org/10.3897/zookeys.326.5344

Zonstein SL, Marusik YM (2017a) Descriptions of the two-eyed African spider genera Chedimanops gen. n. and Hybosidella gen. n. (Araneae, Palpimanidae, Chediminae). African Invertebrates 58(1): 23-47. https://doi.org/10.3897/AfrInvertebr.58.11448

Zonstein SL, Marusik YM (2017b) A redescription of Chedima purpurea Simon, 1873, with notes on the unique copulative stopper mechanism in females (Aranei: Palpimanidae). Arthropoda Selecta 26(3): 225-232.

Zonstein SL, Marusik YM, Omelko MM (2016) Redescription of the type species of Diaphorocellus Simon, 1893 (Araneae, Palpimanidae, Chediminae). African Invertebrates 57(2): 93-103. https://doi.org/10.3897/AfrInvertebr.57.9988

Zonstein SL, Marusik YM, Omelko MM (2018) Redescription of the monotypic genus Scelidomachus Pocock, 1899 (Aranei: Palpimanidae) and its type species. Arthropoda Selecta 27(1): 53-56. https://doi.org/10.15298/arthsel.27.1.07 